\title{
Infrared Spectroscopy and Binding Geometries of Oxygen Atoms Bound to Cationic Tantalum Clusters ${ }^{\dagger}$
}

\author{
André Fielicke,* Philipp Gruene, Marko Haertelt, Dan J. Harding, and Gerard Meijer \\ Fritz-Haber-Institut der Max-Planck-Gesellschaft, Faradayweg 4-6, D-14195 Berlin, Germany
}

Received: March 8, 2010; Revised Manuscript Received: May 10, 2010

The binding of isolated oxygen atoms to small tantalum clusters is investigated using vibrational spectroscopy. Infrared spectra of $\mathrm{Ta}_{n} \mathrm{O}_{0,1,2}{ }^{+}(n=6-11)$ are reported in the range of $90-1100 \mathrm{~cm}^{-1}$, comprising both the internal cluster modes and the adatom's vibrations. The vibrational spectra are compared to the results of DFT calculations for $n=6-8$, which show that the oxygen atoms bind preferentially as 2 -fold bridging adatoms. Addition of one or two $\mathrm{O}$ atoms induces only minor distortions of the underlying metal cluster core.

\section{Introduction}

Understanding the adsorption of atomic and molecular species on surfaces is crucial for obtaining fundamental insights into any surface reaction, especially heterogeneous catalytic reactions. Using the "surface science approach" of studying adsorbate layers on well-ordered metal surfaces has had great success in unraveling, for example, the detailed mechanism of the synthesis of ammonia from its elements on the atomic scale. ${ }^{1}$ Gas-phase metal clusters may be regarded as models for lowcoordinated sites such as adatoms, steps, or kinks on real, defective metal surfaces. Due to the peculiarities in the geometric and electronic structures of these nanosized particles, their chemical behavior can depend strongly on their size and may differ markedly from that of a perfect, extended surface. ${ }^{2}$ This makes them a promising class of materials for developing new tailor-made catalysts of high selectivity.

Recently, many groups have focused on investigating the binding of simple atomic or molecular species to small clusters of transition metals by theoretical means. ${ }^{3,4}$ Such systems can be studied under well-controlled conditions, that is, sizeselectively in the gas phase, but in the past it has proved difficult to obtain detailed information about their structure experimentally. Possible approaches to investigate the structure of such systems are, for instance, threshold photoionization, ${ }^{5,6}$ photoelectron spectroscopy, ${ }^{7,8}$ and IR multiple photon dissociation (IR-MPD) spectroscopy. ${ }^{5,9,10}$ Using a free-electron laser as an intense and tunable IR source for IR-MPD, the interaction of small molecules with transition metal clusters has been studied intensively in the last years ${ }^{11}$ and in many cases strong similarities between the cluster model and the extended surfaces are observed. For instance, carbon monoxide adopts similar binding geometries in both cases and the degree of $\mathrm{C}-\mathrm{O}$ bond activation on the clusters resembles the general trend known for extended surfaces with $\mathrm{CO}$ dissociating on the earlier transition metals and binding molecularly on the later transition metals. $^{12}$

Metal-oxo species play important roles in many catalytic oxidation reactions. ${ }^{13,14}$ Structurally one can distinguish between (i) oxide compounds where the metals are usually in relatively high oxidation states and contain $\mathrm{O}^{2-}$ in the bulk as well as at

\footnotetext{
† Part of the "Reinhard Schinke Festschrift".

* To whom correspondence should be addressed: E-mail: fielicke@ fhi-berlin.mpg.de.
}

the surface and (ii) oxygen adlayers, where the oxygen is (mainly) present as surface species. In most cases, the oxygen is present as an atomic oxide anion, formally $\mathrm{O}^{2-}$, which can be coordinated to a single or more metal centers. Dioxo species (peroxide $\mathrm{O}_{2}{ }^{2-}$ or superoxide $\mathrm{O}_{2}^{-}$) are essential intermediates in the activation of molecular oxygen. ${ }^{15}$

Due to the relevance of high valent oxides of the group $\mathrm{Vb}$ transition metals $(\mathrm{V}, \mathrm{Nb}, \mathrm{Ta})$ in catalytic applications, their clusters have been investigated in great detail by different experimental techniques including anion photoelectron spectroscopy, ${ }^{16-18}$ nonresonant photodissociation, ${ }^{19}$ and IR dissociation spectroscopy; $;^{20-22}$ and their reactions, for example, with hydrocarbons, have been studied. ${ }^{23-25}$ The sequential oxidation of $\mathrm{Ta}_{3}{ }^{-}$has been analyzed using photoelectron spectroscopy. Comparison with density functional theory (DFT) calculations has shown that the first three $\mathrm{O}$ atoms bind in bridging positions while further $\mathrm{O}$ atoms lead to the formation of terminal $\mathrm{Ta}=\mathrm{O}$ units. $^{18}$

Despite the importance of metal oxides, many catalytic reactions occur on partly oxidized metal surfaces, either because the catalyst is a bare metal or because the corresponding metal oxide is partly reduced under reaction conditions. Metal clusters that contain just one or two $\mathrm{O}$ atoms can serve as valuable models for such partially oxidized catalysts. These systems have been studied in much less detail than the corresponding extended metal surfaces. It is interesting, therefore, to investigate the adsorption of oxygen atoms on clusters to determine their binding modes and the extent to which the oxide adatoms induce structural changes of the metal cluster core. More detailed insights into such processes may help the understanding of adsorbate induced surface reconstructions. Past studies have investigated the influence of adsorbed $\mathrm{O}$ atoms on the ionization potential of niobium clusters. ${ }^{26}$ For very small clusters of $M_{3} \mathrm{O}$ stoichiometry $(M=\mathrm{V}, \mathrm{Nb}, \mathrm{Ta})$ vibrationally resolved anion photoelectron spectra have been reported, which are indicative of planar structures with bridging oxygen atoms. ${ }^{27-30}$

In the following, we report on the infrared spectra of tantalum clusters covered by one or two $\mathrm{O}$ atoms. Comparison of the experimental spectra with the results of DFT calculations leads to precise structural assignments of both bare and partly oxidized species, in particular of the $\mathrm{O}$ binding geometries. An analytical model is used to predict force constants and binding angles from the adatom's vibrations. Although experimental vibrational spectra are presented for $\mathrm{Ta}_{n} \mathrm{O}_{0,1,2}{ }^{+}$clusters containing $n=6-11$ 

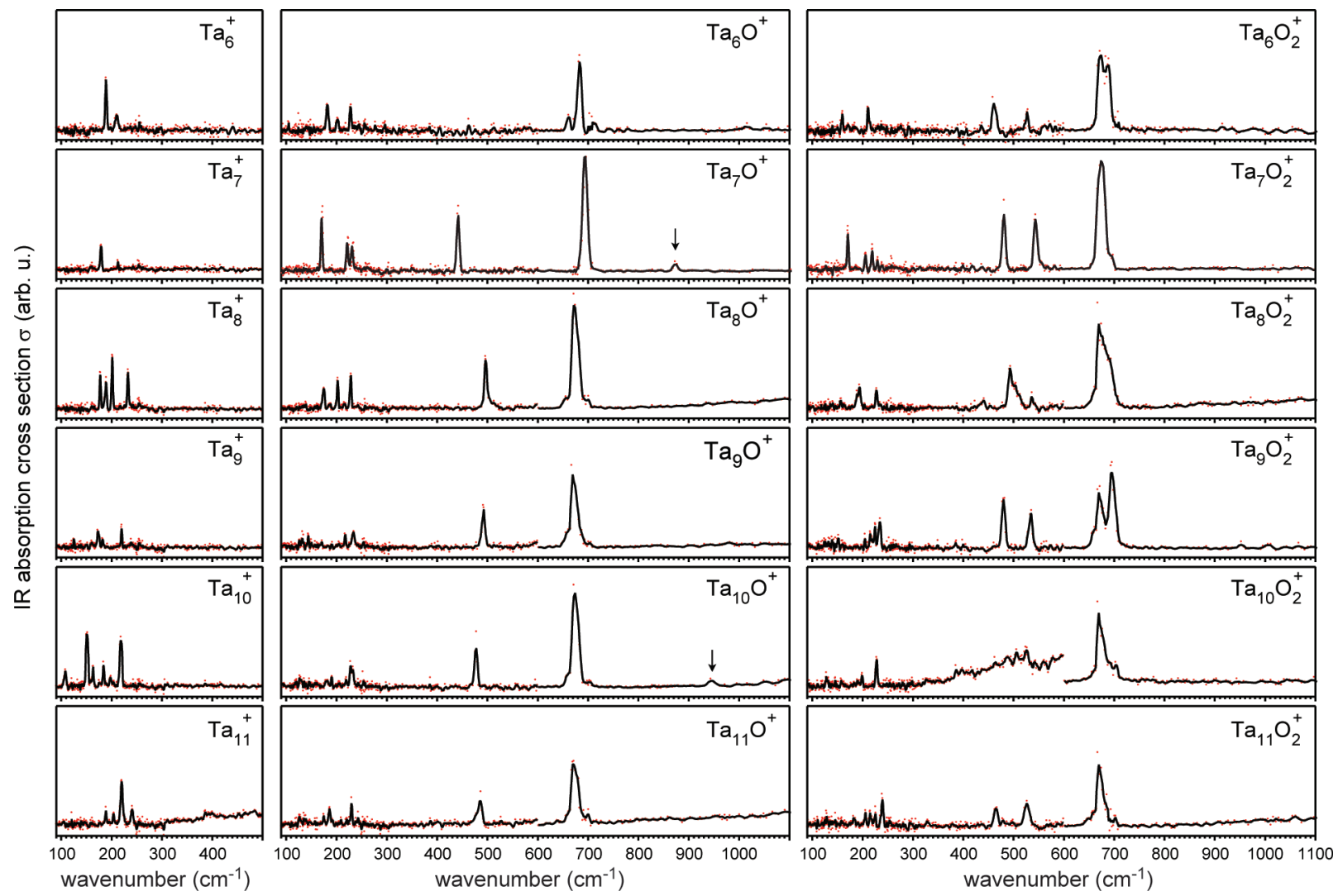

Figure 1. Vibrational spectra of pure $\mathrm{Ta}_{n}{ }^{+}$clusters (left) and clusters with a single (middle) and two (right) oxygen adatoms. The spectra are obtained by IR photodissociation of their complexes with a single $\mathrm{Ar}$ atom (except of the far-IR part of the spectrum of $\mathrm{Ta}_{7} \mathrm{O}^{+}$, which is from the complex with two Ar atoms). Red dots mark the raw data points, and the black line is a three-point running average. IR absorption cross sections are plotted on a common scale for all clusters. Above $600 \mathrm{~cm}^{-1}$ the IR intensities are scaled down by a factor of 5 . The arrows in the spectra of $\mathrm{Ta}_{7} \mathrm{O}^{+}$and $\mathrm{Ta}_{10} \mathrm{O}^{+}$mark bands that can be assigned to overtones $2 \tilde{v}_{a s}$ of the asymmetric $\mathrm{Ta}-\mathrm{O}-\mathrm{Ta}$ stretches.

Ta atoms, we limit the comparison with DFT to $n=6-8$. Strong similarities in the vibrational patterns associated with the oxygen adatoms allow the determination of the O-binding geometries for the larger clusters.

\section{Methods}

Experimental Section. The molecular beam experiment and data evaluation methods have been reported previously. ${ }^{31-33} \mathrm{In}$ short, rare gas tagged clusters are formed via laser ablation of a solid tantalum rod in a pulsed flow of a $\mathrm{He} / \mathrm{Ar}$ gas mixture $(0.2 \% \mathrm{Ar})$. Clusters pass through a copper channel that is cooled to $-95{ }^{\circ} \mathrm{C}$. Partly oxidized clusters and their Ar complexes are formed as byproducts; oxidic contaminants of the tantalum target or trace amounts of water in the He are possible oxygen sources. For some clusters, carbide and water adducts are also observed; however, these can be clearly distinguished due to the high mass resolution provided by the reflectron time-of-flight mass spectrometer employed. The clusters are irradiated with the intense and tunable IR light emitted by the Free Electron Laser for Infrared eXperiments (FELIX), ${ }^{34}$ and the changes in the mass spectra induced by absorption of IR photons are evaluated to obtain cluster size specific IR spectra.

Theoretical Section. Density functional theory is used to investigate the structures of pure and partly oxidized tantalum clusters containing 6-8 Ta atoms and to calculate their vibrational spectra. These calculations have been performed using the TURBOMOLE V6.0 suite of programs. ${ }^{35,36} \mathrm{We}$ apply the meta-generalized gradient functional of Tao, Perdew, Staroverov, and Scuseria (TPSS) ${ }^{37}$ together with balanced triple- $\zeta$ valence basis sets including polarization functions (def2-
TZVP) ${ }^{38}$ as this approach has been found to yield reliable relative energies even for difficult cases such as Au clusters. ${ }^{39}$ For Ta, a Stuttgart-type effective core potential is used that also accounts for scalar-relativistic effects. ${ }^{40}$ All calculations employ the resolution of identity approach (RI-J approximation) ${ }^{41}$ Initial geometries for the pure clusters are taken from the structures identified for clusters of the lighter homologues vanadium ${ }^{31,42}$ and niobium. ${ }^{43}$ Oxygen binding is investigated by probing all possible edge or face-capping sites of the metal clusters, as well as interstitial positions. Vibrational spectra are calculated from analytical second-order geometric derivatives $;{ }^{44}$ all reported frequencies are unscaled. The energy differences include the zero-point vibrational energy corrections.

\section{Results and Discussion}

Experimental IR Spectra. Figure 1 presents the experimental infrared spectra for $\mathrm{Ta}_{n}{ }^{+}, \mathrm{Ta}_{n} \mathrm{O}^{+}$, and $\mathrm{Ta}_{n} \mathrm{O}_{2}{ }^{+}$obtained by photodissociation of their complexes with a single $\mathrm{Ar}$ atom. Vibrational spectra for pure Ta clusters have been reported before $^{33}$ and are included here for comparison with the spectra of the partly oxygenated clusters. In general, the spectra can be divided into two regions: (i) the range of the internal cluster modes in the far-IR below $300 \mathrm{~cm}^{-1}$, where both the pure $\mathrm{Ta}_{n}{ }^{+}$ and the oxidized species show absorption bands; and (ii) the range between 400 and $700 \mathrm{~cm}^{-1}$, where only the $\mathrm{Ta}_{n} \mathrm{O}_{1,2}{ }^{+}$ species absorb IR radiation. The latter range is typical for vibrations involving bridging or higher coordinated $\mathrm{O}$ atoms. For instance, in $\mathrm{Ta}_{3} \mathrm{O}$ the metal-oxygen symmetric stretching fundamental frequency is found at $710 \pm 15 \mathrm{~cm}^{-1} \cdot{ }^{27}$ Terminal $M=\mathrm{O}$ bonds are characterized by bands between 900 and 1000 

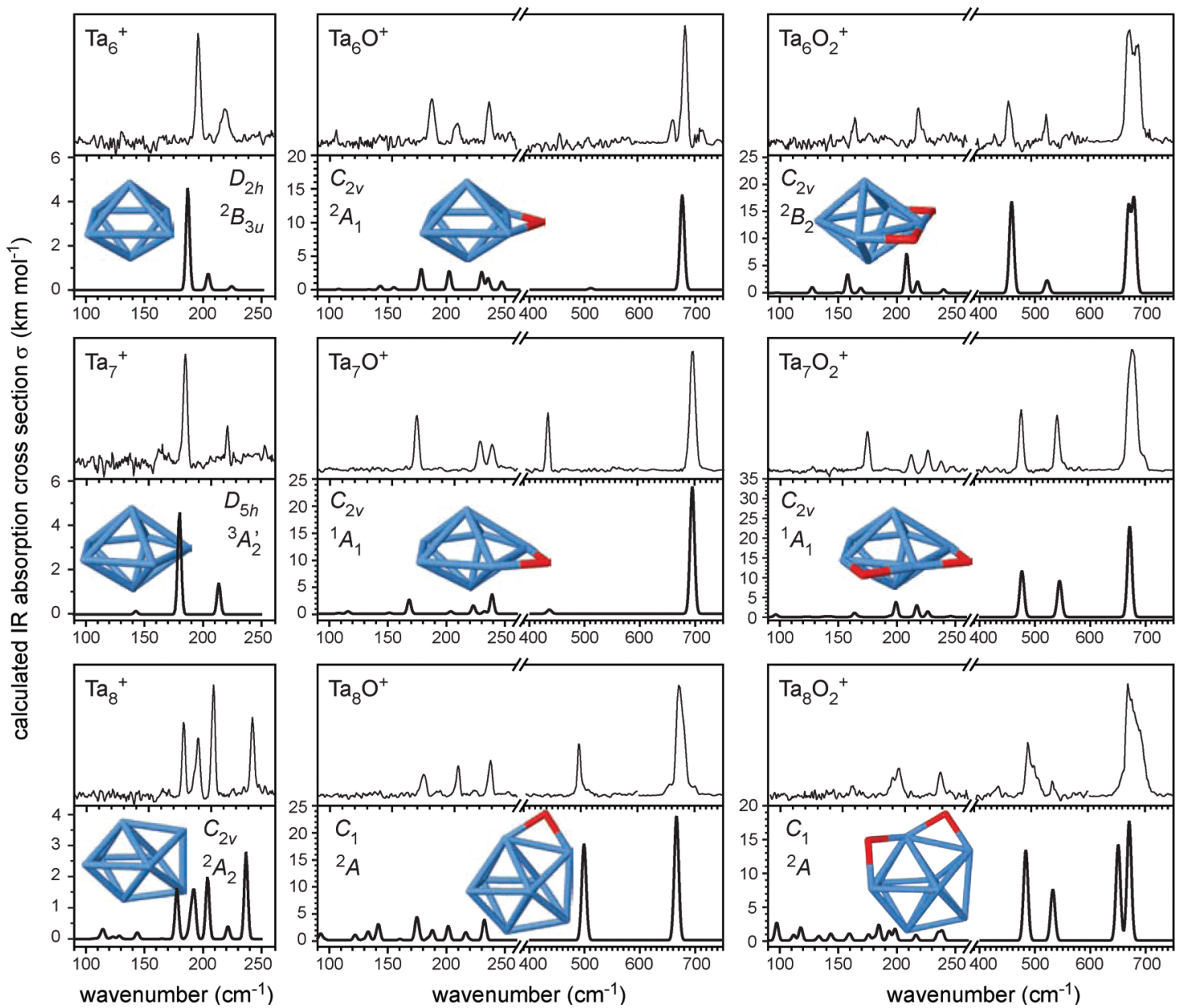

Figure 2. Comparison of experimental vibrational spectra to calculated spectra for the lowest energy isomers found for $\mathrm{Ta}_{n} \mathrm{O}_{0,1,2}{ }^{+}$. Experimental and calculated IR intensities above $600 \mathrm{~cm}^{-1}$ are divided by a factor of 5. The calculated stick spectra are folded with a Gaussian line-width function of $3 \mathrm{~cm}^{-1}$ full width at half-maximum in the far-IR and of $8 \mathrm{~cm}^{-1}$ above $400 \mathrm{~cm}^{-1}$. The molecular symmetries and electronic states are given for the calculated structures.

$\mathrm{cm}^{-1}$ as found, for example, for matrix-isolated $\mathrm{TaO}\left(961 \mathrm{~cm}^{-1}\right)$ and $\mathrm{TaO}_{2}\left(912\right.$ and $\left.965 \mathrm{~cm}^{-1}\right),{ }^{46}$ or highly oxidized $\mathrm{Ta}_{x} \mathrm{O}_{y}{ }^{+}$ clusters $\left(995 \mathrm{~cm}^{-1}\right){ }^{22}$

Structures of $\mathrm{Ta}_{n}{ }^{+}(n=6-8)$. The lowest energy structures of the pure tantalum cluster cations identified by DFT are a rectangular bipyramid $\left(D_{2 h}\right)$ for $\mathrm{Ta}_{6}{ }^{+}$, a pentagonal bipyramid $\left(D_{5 h}\right)$ for $\mathrm{Ta}_{7}{ }^{+}$, and a distorted doubly capped octahedron for $\mathrm{Ta}_{8}{ }^{+}\left(C_{2 v}\right)$. These structures are very similar to the ones of the cationic vanadium and niobium clusters, although $\mathrm{V}_{7}{ }^{+}$and $\mathrm{Nb}_{7}{ }^{+}$ are more distorted from $D_{5 h}$ symmetry. ${ }^{42,43} \mathrm{Ta}_{6}{ }^{+}$and $\mathrm{Ta}_{8}{ }^{+}$are found to have doublet electronic ground states ${ }^{2} \mathrm{~B}_{3 \mathrm{u}}$ and ${ }^{2} \mathrm{~A}_{2}$, respectively, whereas for $\mathrm{Ta}_{7}{ }^{+}$the ${ }^{3} \mathrm{~A}_{2}^{\prime}$ triplet state is lower than the ${ }^{1} \mathrm{~A}^{\prime \prime}$ singlet state isomer (which distorts to $C_{s}$ symmetry) by $0.21 \mathrm{eV}$. Ta-Ta bond distances in $\mathrm{Ta}_{6}{ }^{+}$are 279 and $299 \mathrm{pm}$ within the rectangular base plane and $257 \mathrm{pm}$ to the capping atoms; in $\mathrm{Ta}_{7}{ }^{+}$they are $257 \mathrm{pm}$ within the base plane and 271 pm toward the caps; and between 254 and 290 pm in $\mathrm{Ta}_{8}{ }^{+}$. Similar, however more distorted structures, have been proposed before for the neutral tantalum clusters. ${ }^{45}$

The comparison of the calculated IR spectra for these isomers with the experimental spectra shows good agreement (Figure 2), allowing the conclusion that these are the cluster species present in the experiment. Other starting geometries, for example, the bicapped tetrahedral $\mathrm{Ta}_{6}{ }^{+}$, are observed to collapse into the reported structures. The attached rare gas atoms appear to have no major influence on the structures and IR spectra, as a good agreement is already observed without considering the rare gas messengers in the calculations. This is similar to the observations for $\mathrm{Nb}$ clusters ${ }^{43}$ but opposed to the strong influence of the Ar messenger atoms found for small cationic cobalt clusters, which can be related to a stronger electrostatic interaction between the comparably small Co atoms and $\mathrm{Ar}^{47}$

Binding of $\mathrm{O}$ Adatoms on $\mathrm{Ta}_{n}{ }^{+}(n=6-8)$. Figure 2 compares the experimental spectra with the calculated spectra of the lowest energy isomers identified for the $\mathrm{Ta}_{n} \mathrm{O}_{0,1,2}{ }^{+}$species (see ESI for details). In all cases the oxygen is found in bridge bound positions. Oxygen atoms initially placed into face-capping positions tend to relax into bridging geometries. All the identified low energy isomers of the O-adsorbates possess the lowest possible spin multiplicities, that is, doublet electronic states for $\mathrm{Ta}_{6,8} \mathrm{O}_{1,2}{ }^{+}$and singlet states for $\mathrm{Ta}_{7} \mathrm{O}_{1,2}{ }^{+}$.

For $\mathrm{Ta}_{6}{ }^{+}$, three dissimilar bridging positions exist: either spanning the short or long edges of the bipyramid's rectangular base or the edges toward the apexes. The latter structure is found to be $0.93 \mathrm{eV}$ less stable than the isomer where the $\mathrm{O}$ atom bridges the shorter edge of the base. This ${ }^{2} \mathrm{~A}_{1}$ structure is the most stable found, with an $\mathrm{O}$ binding energy of $7.88 \mathrm{eV}$. Bridging the longer edges appears to be unfavorable, and such a structure relaxes into the putative ground state isomer. Its predicted IR spectrum compares well with the experimental spectrum. The intense band at $683 \mathrm{~cm}^{-1}$ can be related to the symmetric stretch $\tilde{\nu}_{s}$ of the $\mathrm{Ta}-\mathrm{O}-\mathrm{Ta}$ bridge, whereas the asymmetric stretch $\tilde{v}_{a s}$ has very low IR intensity and is not observed in the experiment (see Table 1). The far-IR part of 
TABLE 1: Experimental and Calculated (for $n=6-8$ ) Stretching Frequencies $\left(\tilde{v}_{a s}, \tilde{v}_{s}\right)$ for the 2-Fold Bridging $O$ Adatoms in $\mathrm{Ta}_{n} \mathrm{O}^{+a}$

\begin{tabular}{lcccccc}
\hline & $\begin{array}{c}\tilde{v}_{a s} \\
\left(\mathrm{~cm}^{-1}\right)\end{array}$ & $\begin{array}{c}\tilde{v}_{s} \\
\left(\mathrm{~cm}^{-1}\right)\end{array}$ & $\begin{array}{c}\tilde{v}_{a s} \\
(D F T)\left(\mathrm{cm}^{-1}\right)\end{array}$ & $\begin{array}{c}\tilde{v}_{s} \\
(D F T)\left(\mathrm{cm}^{-1}\right)\end{array}$ & $\begin{array}{c}\tilde{v}_{e, a s} \\
\left(\mathrm{~cm}^{-1}\right)\end{array}$ & $\begin{array}{c}\tilde{v}_{e, a s} \tilde{x}_{e, a s} \\
\left(\mathrm{~cm}^{-1}\right)\end{array}$ \\
\hline 6 & $b$ & 683 & 511 & 677 & & \\
7 & 440 & 695 & 436 & 696 & $447 \pm 1$ & $3.5 \pm 1.5$ \\
8 & 497 & 675 & 498 & 666 & & \\
9 & 492 & 672 & & & & \\
10 & 477 & 675 & & & $486 \pm 1$ & $4.5 \pm 1.5$ \\
11 & 485 & 674 & & & &
\end{tabular}

${ }^{a}$ For $n=7$ and 10, the observation of vibrational overtones allows the determination of the harmonic frequencies of the asymmetric stretch and the corresponding quadratic terms of the anharmonicities. The experimental frequencies have an estimated uncertainty of $\pm 1 \mathrm{~cm}^{-1}$. ${ }^{b}$ Band is not observed in the experiment.

TABLE 2: Experimental and Calculated (for $n=6-8$ ) Stretching Frequencies $\left(\tilde{v}_{a s}, \tilde{v}_{s}\right)$ for the 2-Fold Bridging $O$ Adatoms in $\mathrm{Ta}_{n} \mathrm{O}_{2}{ }^{+}$

\begin{tabular}{lclcc}
\hline$n$ & $\tilde{v}_{a s}\left(\mathrm{~cm}^{-1}\right)$ & $\tilde{v}_{s}\left(\mathrm{~cm}^{-1}\right)$ & $\tilde{v}_{a s}(D F T)\left(\mathrm{cm}^{-1}\right)$ & $\tilde{v}_{s}(D F T)\left(\mathrm{cm}^{-1}\right)$ \\
\hline 6 & 461,527 & 673,687 & 459,522 & 670,679 \\
7 & 482,545 & 677 & 477,545 & 671,672 \\
8 & 497,537 & 678 & 484,534 & 651,671 \\
9 & 480,534 & 671,696 & & \\
10 & $a$ & 672 & & \\
11 & 465,526 & 672 & &
\end{tabular}

${ }^{a}$ Several unresolved bands.

the spectrum also shows good agreement between experiment and theory. Two rather weak bands appear next to the intense $\tilde{v}_{s}$ band at $683 \mathrm{~cm}^{-1}$. Similar features, although weaker and less well resolved, can also be seen for other sizes, always shifted by $20-30 \mathrm{~cm}^{-1}$ from the main $\tilde{v}_{s}$ peak. Probably, these signals are van der Waals sidebands stemming from combinations of $\tilde{v}_{S}$ with the cluster-Ar modes. ${ }^{48}$

The second $\mathrm{O}$ atom binds to $\mathrm{Ta}_{6} \mathrm{O}^{+}$most strongly on the edge of the base neighboring the existing $\mathrm{Ta}-\mathrm{O}-\mathrm{Ta}$ bridge to form a $C_{2 v}$ symmetric isomer in a ${ }^{2} \mathrm{~B}_{2}$ state. Binding to the opposite edge of the base leads to an $0.18 \mathrm{eV}$ less stable ${ }^{2} \mathrm{~B}_{1 \mathrm{u}}$ isomer of $D_{2 h}$ symmetry. Addition to the other edges is energetically even less favorable. The lowest energy isomer of $\mathrm{Ta}_{6} \mathrm{O}_{2}{ }^{+}$found in the calculations exhibits an IR spectrum, which is very similar to the experimental one. The highest energy band centered at $681 \mathrm{~cm}^{-1}$ is split due to the in-phase and out-of-phase symmetric stretches of the two Ta-O-Ta bridges, found at 679 and 670 $\mathrm{cm}^{-1}$ in the calculations. The asymmetric $\mathrm{Ta}-\mathrm{O}-\mathrm{Ta}$ stretches are observed at 461 and $527 \mathrm{~cm}^{-1}$ and calculated at 459 and $522 \mathrm{~cm}^{-1}$, respectively (see Table 2). The $D_{2 h}$ isomer has a rather different IR spectrum, showing no splitting for the symmetric $\mathrm{Ta}-\mathrm{O}-\mathrm{Ta}$ stretches, and also a very different band pattern in the range of the asymmetric stretches, having one IR-inactive $\tilde{v}_{a s}$ band at $484 \mathrm{~cm}^{-1}$ and the second at $504 \mathrm{~cm}^{-1}$. The lengths of the O-spanned $\mathrm{Ta}-\mathrm{Ta}$ bonds in the lowest energy isomers of $\mathrm{Ta}_{6} \mathrm{O}^{+}$and $\mathrm{Ta}_{6} \mathrm{O}_{2}{ }^{+}$are very similar, 277 and $278 \mathrm{pm}$, respectively. The initial metal cluster structure is only slightly distorted, the longer bonds in the bipyramid's base are elongated to $308 \mathrm{pm}$. However, in $\mathrm{Ta}_{6} \mathrm{O}_{2}{ }^{+}$, the $\mathrm{Ta}_{6}{ }^{+}$cluster core distorts from its initial $D_{2 h}$ symmetry to $C_{2 v}$; while the bipyramid's base is initially rectangular with edges of 279 and $299 \mathrm{pm}$ in length, the two longer, unbridged, bonds of the base of $311 \mathrm{pm}$ length are now adjacent. This shows how the metal cluster structure adapts upon $\mathrm{O}$ adsorption, event though there is not a major restructuring. In the most stable isomer of $\mathrm{Ta}_{6} \mathrm{O}_{2}{ }^{+}$the second $\mathrm{O}$ atom is, at $7.13 \mathrm{eV}$, slightly weaker bound than the first one.
As breaking the $\mathrm{O}-\mathrm{O}$ bond in dioxygen takes $5.1 \mathrm{eV}$, the reaction $\mathrm{Ta}_{6}{ }^{+}+\mathrm{O}_{2} \rightarrow \mathrm{Ta}_{6} \mathrm{O}_{2}{ }^{+}$becomes exothermic by $9.9 \mathrm{eV}$. This compares well with the initial heat of adsorption of $\mathrm{O}_{2}$ on Ta surfaces, which is $887 \mathrm{~kJ} \mathrm{~mol}^{-1}$ or $9.2 \mathrm{eV}^{49}$

Two different positions for attaching bridging $\mathrm{O}$ atoms are present on the pentagonal bipyramid of $\mathrm{Ta}_{7}{ }^{+}$, namely on the base and on the edges toward the apexes. Again, $\mathrm{O}$ attachment to the base is energetically favored by $0.38 \mathrm{eV}$, compared to the latter position. The calculated O-binding energy is $7.26 \mathrm{eV}$ for the base bound $\mathrm{O}$ atom in this ${ }^{1} \mathrm{~A}_{1}$ state isomer. $\mathrm{A}{ }^{3} \mathrm{~B}_{1}$ state isomer of similar structure is calculated to be quasi-isoenergetic, just $0.01 \mathrm{eV}$ higher in energy. However, while the calculated IR spectrum of the singlet state isomer agrees relatively well with the experiment-only the intensity of the asymmetric Ta-O-Ta stretch $\tilde{v}_{a s}$ observed at $440 \mathrm{~cm}^{-1}$ appears too low-for the triplet state a rather different spectrum is predicted with $\tilde{v}_{s}$ red-shifted by $26 \mathrm{~cm}^{-1}$ and $\tilde{v}_{a s}$ blue-shifted by $22 \mathrm{~cm}^{-1}$ compared to the values for the singlet state isomer (see Table 1). A third, more distorted, isomer in a ${ }^{1} \mathrm{~A}$ electronic state with a nonplanar, buckled, pentagonal base of the bipyramid is 0.20 $\mathrm{eV}$ higher in energy.

A second $\mathrm{O}$ atom is preferentially bound adjacent to the first one. The lowest energy structure identified for $\mathrm{Ta}_{7} \mathrm{O}_{2}{ }^{+}$is of $C_{2 v}$ symmetry and has both O-bridges in the base plane as in $\mathrm{Ta}_{6} \mathrm{O}_{2}{ }^{+}$. The second $\mathrm{O}$ atom is bound by $7.73 \mathrm{eV}$ in this ${ }^{1} \mathrm{~A}_{1}$ isomer. $\mathrm{A}$ similar ${ }^{3} \mathrm{~B}_{2}$ state isomer is $0.18 \mathrm{eV}$ higher in energy. The second lowest energy structural isomer $\left(+0.52 \mathrm{eV},{ }^{1} \mathrm{~A}\right)$ contains an O-bridge between the apex and a Ta atom of the base that is connected to the first $\mathrm{O}$ atom. The vibrational pattern for the identified lowest energy isomer agrees well in the range of the $\mathrm{Ta}-\mathrm{O}-\mathrm{Ta}$ stretches, while in the far-IR, the predicted band pattern appears slightly red-shifted (by $\approx 5 \mathrm{~cm}^{-1}$ ) with respect to the experiment and the band at $170 \mathrm{~cm}^{-1}$ is predicted with considerably lower intensity. Unlike in $\mathrm{Ta}_{6} \mathrm{O}_{2}{ }^{+}$, the $\tilde{v}_{s}$ band of $\mathrm{Ta}_{7} \mathrm{O}_{2}{ }^{+}$does not appear split, the calculations find a shift between the in-phase and out-of-phase vibrations of only $1 \mathrm{~cm}^{-1}$, which would not be resolved in the experiment. Overall, the assignments for $\mathrm{Ta}_{7} \mathrm{O}^{+}$and $\mathrm{Ta}_{7} \mathrm{O}_{2}{ }^{+}$allow the conclusion that the high spin (triplet) state of $\mathrm{Ta}_{7}{ }^{+}$is quenched upon adsorption of a single $\mathrm{O}$ atom. The $\mathrm{O}$-bridged $\mathrm{Ta}-\mathrm{Ta}$ bond distance is very short in $\mathrm{Ta}_{7} \mathrm{O}^{+}, 250 \mathrm{pm}$, and is $275 \mathrm{pm}$ in $\mathrm{Ta}_{7} \mathrm{O}_{2}{ }^{+}$. The latter value is similar to the bridged $\mathrm{Ta}-\mathrm{Ta}$ distances in $\mathrm{Ta}_{6} \mathrm{O}_{1,2}{ }^{+}$. The short $\mathrm{Ta}-\mathrm{Ta}$ bond in $\mathrm{Ta}_{7} \mathrm{O}^{+}$and the related small $\mathrm{Ta}-\mathrm{O}-\mathrm{Ta}$ bond angle are the reasons for the relatively strong shifts of $\tilde{v}_{a s}\left(\approx-50 \mathrm{~cm}^{-1}\right)$ and $\tilde{v}_{s}\left(\approx+20 \mathrm{~cm}^{-1}\right)$ compared to the values for all other clusters (see Table 1).

The most stable isomer of $\mathrm{Ta}_{8} \mathrm{O}^{+}$identified is slightly distorted from $C_{s}$ symmetry, and its structure is shown in Figure 2. The $\mathrm{O}$ atom is bound in this isomer by $7.28 \mathrm{eV}$. Its predicted spectrum fits the experimental one in the range of the $\mathrm{Ta}-\mathrm{O}-\mathrm{Ta}$ stretches and also in the far-IR range between 150 and $250 \mathrm{~cm}^{-1}$ a clear match is seen, with a pattern of five distinct bands. Several other isomers are found, which are at least $0.47 \mathrm{eV}$ higher in energy. The next lowest isomer contains an O-bridge between the two Ta atoms face-capping the distorted octahedron in $\mathrm{Ta}_{8}{ }^{+}$, while the lowest energy isomer with face-capping oxygen is $0.54 \mathrm{eV}$ higher as compared to the identified structure.

In the lowest energy structure found for $\mathrm{Ta}_{8} \mathrm{O}_{2}{ }^{+}$the $\mathrm{O}$ atom adds with a binding energy of $7.49 \mathrm{eV}$ to the lowest energy isomer of $\mathrm{Ta}_{8} \mathrm{O}^{+}$in a bridging site on the octahedral subunit of $\mathrm{Ta}_{8}{ }^{+}$neighboring the existing O-bridge. Its spectrum explains the features in the $\mathrm{Ta}-\mathrm{O}-\mathrm{Ta}$ stretch-region reasonably, but the agreement in the far-IR part is less convincing. The next-lowest isomer $(+0.31 \mathrm{eV})$, again based on the structure of $\mathrm{Ta}_{8} \mathrm{O}^{+}$, has 
the second O-bridge spanning the face-capping atoms attached to the octahedral subunit. For this isomer the bands of the asymmetric $\mathrm{Ta}-\mathrm{O}-\mathrm{Ta}$ stretches are significantly red-shifted compared to the experimental findings, and also at lower frequency its spectrum does not fully agree. The calculations predict a significant splitting for the symmetric $\mathrm{Ta}-\mathrm{O}-\mathrm{Ta}$ stretching modes of $19 \mathrm{~cm}^{-1}$; however, in contrast to $\mathrm{Ta}_{6,7} \mathrm{O}_{2}{ }^{+}$, the stretches of the two $\mathrm{Ta}-\mathrm{O}-\mathrm{Ta}$ bridges hardly couple. It might be that for $\mathrm{Ta}_{8} \mathrm{O}_{2}{ }^{+}$the isomer present in the experiment has not been found in our calculations, although for the identified lowest energy isomer the good agreement in the range of the $\mathrm{Ta}-\mathrm{O}-\mathrm{Ta}$ stretches indicates that the $\mathrm{O}$-binding geometries are likely to be correct. Upon addition of the O-bridges the $\mathrm{Ta}-\mathrm{Ta}$ bonds become continuously more elongated, that is, for the primary bridge from $266 \mathrm{pm}$ for the bare cluster to 275 and $283 \mathrm{pm}$ in $\mathrm{Ta}_{8} \mathrm{O}^{+}$and $\mathrm{Ta}_{8} \mathrm{O}_{2}{ }^{+}$, respectively, and from $263 \mathrm{pm}$ in $\mathrm{Ta}_{8}{ }^{+}$to $277 \mathrm{pm}$ in $\mathrm{Ta}_{8} \mathrm{O}_{2}{ }^{+}$for the second bridge.

Binding Geometry and Force Constants. The comparison between experimental spectra and theoretical predictions for $\mathrm{Ta}_{n} \mathrm{O}_{1,2}{ }^{+}(n=6-8)$ clearly reveals that the oxygen atoms bind in a 2 -fold bridging manner. For the larger clusters very similar spectral patterns are experimentally found in the range of the $\mathrm{Ta}-\mathrm{O}-\mathrm{Ta}$ stretches (Figure 1), from which we conclude that oxygen binds to them in the same geometry. The binding on those small clusters is, however, different to the O-layers on the $\mathrm{Ta}(100)$ surface, where it has been concluded that the $\mathrm{O}$ atoms are in a 4-fold, quasi-tetrahedral, coordination. ${ }^{50}$

In the following, we will focus on a qualitative analysis of the experimental IR spectra of $\mathrm{Ta}_{n} \mathrm{O}^{+}$in the range of the $\mathrm{M}-\mathrm{O}-\mathrm{M}$ stretches in order to draw conclusions on the detailed oxygen binding geometry based on the experiment alone. The outcome can be compared to the results from the DFT calculations.

Vibrations of adatoms bound to a rigid substrate of infinite mass can be described by simple analytical models. ${ }^{51,52}$ According to the next nearest neighbor central force model the frequencies of the symmetric $\left(v_{s}\right)$ and asymmetric $\left(v_{a s}\right)$ stretches for a 2-fold symmetrical bridge only depend on the stretching force constant $k$, the adatom's mass $m_{O}$ and the Ta-O-Ta bond angle $2 \alpha$ :

$$
v_{s}^{2}=\frac{2 k}{m_{O}} \cos ^{2} \alpha \quad v_{a s}^{2}=\frac{2 k}{m_{O}} \sin ^{2} \alpha
$$

This gives the opportunity to calculate the $\mathrm{Ta}-\mathrm{O}-\mathrm{Ta}$ bond angle from $v_{s}$ and $v_{a s}$, as

$$
2 \alpha=2 \arccos \frac{v_{s}}{\sqrt{v_{s}^{2}+v_{a s}^{2}}}
$$

The values obtained for the $\mathrm{Ta}-\mathrm{O}-\mathrm{Ta}$ bond angles $2 \alpha$ are compared to the structural parameters from the DFT calculations in Table 3. Although the absolute values of the $\mathrm{Ta}-\mathrm{O}-\mathrm{Ta}$ bond angles as determined from the stretching frequencies and the DFT calculations differ significantly, they follow the same trend, showing for $n=7$ a clearly smaller angle, which relates to the rather short $\mathrm{Ta}-\mathrm{Ta}$ bond in the 5 -membered ring of $\mathrm{Ta}_{7}{ }^{+}$. The ratios of the $\mathrm{Ta}-\mathrm{O}-\mathrm{Ta}$ bond angles, as predicted by DFT and determined from the stretching frequencies, are relatively constant with $1.23,1.24$, and 1.24 for $n=6,7$, and 8, respectively.
TABLE 3: Force Constants $(k)$ and Structural Parameters for the 2-Fold Bridging $\mathrm{O}$ Adatoms in $\mathrm{Ta}_{n} \mathrm{O}^{+}$from the Adatom Vibrational Model and from DFT Calculations (for $n=6-8)^{a}$

\begin{tabular}{lccccc}
\hline$k$ & $k(\mathrm{DFT})$ & $2 \alpha$ & $2 \alpha(\mathrm{DFT})$ & $d(\mathrm{Ta}-\mathrm{O})$ \\
$n$ & $\left(\mathrm{Nm}^{-1}\right)$ & $\left(\mathrm{Nm}^{-1}\right)$ & $\left({ }^{\circ}\right)$ & $\begin{array}{c}\left.{ }^{\circ}\right) \\
(\mathrm{DFT})(\mathrm{pm})\end{array}$ \\
\hline 6 & $343^{b}$ & 398 & 74 & 91.8 & $193.1,193.1$ \\
7 & 319 & 355 & 65 & 80.0 & $194.8,194.8$ \\
8 & 331 & 326,439 & 73 & 90.4 & $191.0,197.1$ \\
9 & 327 & & 72 & & \\
10 & 322 & & 70 & & \\
11 & 325 & & 71 & &
\end{tabular}

${ }^{a}$ The DFT Ta-O-Ta bond angle $2 \alpha$ is directly taken from the calculated geometry. ${ }^{b}$ Value of $\tilde{v}_{a s}$ for calculating $k$ is taken from the DFT calculations.

Stretching force constants $k$ for the $\mathrm{Ta}-\mathrm{O}$ bond can be calculated after combining equations eq 1 , which yield

$$
k=\frac{\left(v_{s}^{2}+v_{a s}^{2}\right)}{2} m_{O}=4 \pi^{2} c_{0}^{2} \frac{\left(\tilde{v}_{s}^{2}+\tilde{v}_{a s}^{2}\right)}{2} \frac{M_{O}}{N_{A}}
$$

This assumes a symmetrically bound oxygen adatom for which both $\mathrm{Ta}-\mathrm{O}$ stretching force constants are identical. The comparison with the calculated force constants is included in Table 3. For asymmetric cases, as in $\mathrm{Ta}_{8} \mathrm{O}^{+}$, the value obtained from eq 3 can be compared to an average value of force constants obtained by DFT. The main reason for the observed differences between the predictions of the nearest neighbor force constant model and the results from the DFT calculations is probably that the assumption of a static substrate in the analytical model is not fully valid, as in the vibrations assigned to $\mathrm{Ta}-\mathrm{O}-\mathrm{Ta}$ stretches, significant displacements of Ta atoms within the cluster also occur.

Anharmonicities. For most of the partly oxidized Ta clusters the vibrational bands are exclusively found below $700 \mathrm{~cm}^{-1}$. For two specific sizes, $\mathrm{Ta}_{7} \mathrm{O}^{+}$and $\mathrm{Ta}_{10} \mathrm{O}^{+}$, signals are detected at higher frequencies, at 873 and $945 \mathrm{~cm}^{-1}$, respectively. For stretches of terminal oxygen groups, $\mathrm{Ta}=\mathrm{O}$, the observed frequencies appear rather low (see above). However, instead of being vibrational fundamentals, these signals could also be due to their overtones or combination bands. Indeed, these frequencies are close to, although a little lower than twice the experimentally observed frequency of the asymmetric stretching modes of the O-bridges in $\mathrm{Ta}_{7} \mathrm{O}^{+}$and $\mathrm{Ta}_{10} \mathrm{O}^{+}$. From the frequencies of the vibrational fundamentals and their first overtones the harmonic stretching frequencies $\tilde{\nu}_{e, a s}$ and quadratic terms of the anharmonicities $\tilde{\nu}_{e, a s} \tilde{x}_{e, a s}$ are obtained (see Table 1).

Although the overtone bands appear rather weak in Figure 1 , it should be kept in mind that the experimental IR intensities are scaled down by a factor of 5 in this spectral range. Such intense overtones are rather unusual. However, it could well be that, at the high frequency of the overtone, the absorption of just a single IR photon is sufficient to induce the dissociation of the rare gas complex while at lower frequency this turns into a two- or multiple-photon process. This could explain a more efficient dissociation and related to this a seemingly high absorption cross section for the overtones.

Knowledge of the anharmonicity of the adsorbate binding potential allows for more detailed insights into surface processes such as vibrational coupling with the substrate phonons, adatom diffusion, or chemical reactions. For surface adsorbates the 
anharmonic terms are usually determined from temperature dependent shifts and changes in the line-shape of the vibrational bands ${ }^{53}$ or by overtone spectroscopy. ${ }^{54}$ For vibrational anharmonicities of oxygen adatoms little experimental data is currently available. Our values of $\tilde{v}_{e, a s} \tilde{x}_{e, a s}$ may be compared to data for surface oxygen in long-bridge sites. However, in this geometry, binding to the next-nearest metal atoms (e.g., 1.8 vs $2.0 \AA$ for $\left.\mathrm{Cu}(110)-(2 \times 1)-\mathrm{O}^{55}\right)$ can not be fully neglected, leading to a 4-fold coordinated $\mathrm{O}$ atom. Additionally, due to surface selection rules, the asymmetric stretch is not accessible in many techniques used in surface vibrational spectroscopy, for example, high-resolution electron energy loss spectroscopy. Nevertheless, the $\tilde{v}_{e, a s} \tilde{x}_{e, a s}$ values obtained for $\mathrm{O}$ bound to small tantalum clusters, 3.5 and $4.5 \mathrm{~cm}^{-1}$, are of the same order as found for the symmetric oxygen-metal stretch for long-bridge sites, that is, 2.3 and $5.3 \mathrm{~cm}^{-1}$ for $\mathrm{Cu}(110)-(2 \times 1)-\mathrm{O}$ and $\operatorname{Ag}(110)-(2 \times 1)-O$, respectively. ${ }^{56,57}$

\section{Conclusions}

We have reported the vibrational spectra of small tantalum clusters and their surface adducts with one and two $\mathrm{O}$ atoms. The IR spectra have been obtained by IR-MPD of the complexes of the clusters with single Ar atoms. They provide, by comparison with the results of DFT calculations, detailed insights into the structures of the metal cluster core and the binding sites and coordination of the attached oxygen atoms. The bare clusters, $\mathrm{Ta}_{6-8}{ }^{+}$, are found to have similar geometries to their lighter homologues vanadium and niobium, that is, a rectangular bipyramid, a pentagonal bipyramid, and a distorted bicapped octahedron. In all cases the oxygen atoms are found to occupy two-fold bridging positions on the cluster's surface. Furthermore, if a second oxygen atom is added it prefers binding to adjacent sites. Although the clusters are found to adapt to the surface bound oxygen by slight changes of their geometries, no major structural rearrangements are observed. Using an analytical model, information about the force constants and binding angles of the oxygen atoms to the cluster can be deduced directly from the experimental data.

Acknowledgment. We gratefully acknowledge the support of the Stichting voor Fundamenteel Onderzoek der Materie (FOM) in providing beam time on FELIX. The authors thank the FELIX staff for their skillful assistance, in particular Dr. B. Redlich and Dr. AFG van der Meer. This work is supported by the Cluster of Excellence "Unifying Concepts in Catalysis" coordinated by the Technische Universität Berlin and funded by the Deutsche Forschungsgemeinschaft. We thank Dr. B. Sartakov for valuable discussions.

Supporting Information Available: Experimental IR spectra as well as Cartesian coordinates and calculated IR spectra of all cluster isomers discussed in the text are available as supporting electronic information. This material is available free of charge via the Internet at http://pubs.acs.org.

\section{References and Notes}

(1) Ertl, G. Angew. Chem., Int. Ed. 2008, 47, 3524

(2) Haruta, M.; Daté, M. Appl. Catal. A: General 2001, 222, 427.

(3) See for instance: Duarte, H.; Salahub, D. Top Catal. 1999, 9, 123. Yoon, B.; Hakkinen, H.; Landman, U. J. Phys. Chem. A 2003, 107, 4066 Gutsev, G. L.; Mochena, M. D.; Johnson, E.; Bauschlicher, C. W., Jr. J. Chem. Phys. 2006, 125, 194312. Genest, A.; Krüger, S.; Rösch, N. J. Phys. Chem. A 2008, 112, 7739.

(4) Harding, D.; Mackenzie, S. R.; Walsh, T. R. J. Phys. Chem. B 2006, 110, 18272. Harding, D. J.; Davies, R. D. L.; Mackenzie, S. R.; Walsh, T. R. J. Chem. Phys. 2008, 129, 124304.
(5) Knickelbein, M. B.; Koretsky, G. M.; Jackson, K. A.; Pederson, M. R.; Hajnal, Z. J. Chem. Phys. 1998, 109, 10692.

(6) Pedersen, D. B.; Rayner, D. M.; Simard, B.; Addicoat, M. A.; Buntine, M. A.; Metha, G. F.; Fielicke, A. J. Phys. Chem. A 2004, 108, 964.

(7) Kim, Y. D.; Ganteför, G. J. Mol. Struct. 2004, 692, 139.

(8) Zhai, H.-J.; Kiran, B.; Dai, B.; Li, J.; Wang, L.-S. J. Am. Chem. Soc. 2005, 127, 12098.

(9) Rayner, D. M.; Lian, L.; Fournier, R.; Mitchell, S. A.; Hackett, P. A. Phys. Rev. Lett. 1995, 74, 2070.

(10) Dietrich, G.; Krückeberg, S.; Lützenkirchen, K.; Schweikhard, L.; Walther, C. J. Chem. Phys. 2000, 112, 752.

(11) Simard, B.; Dénommée, S.; Rayner, D. M.; van Heijnsbergen, D.; Meijer, G.; von Helden, G. Chem. Phys. Lett. 2002, 357, 195. Fielicke, A.; von Helden, G.; Meijer, G.; Simard, B.; Dénommée, S.; Rayner, D. M. J. Am. Chem. Soc. 2003, 125, 11184. Jaeger, T. D.; Fielicke, A.; von Helden, G.; Meijer, G.; Duncan, M. A. Chem. Phys. Lett. 2004, 392, 409. Swart, I.; de Groot, F. M. F.; Weckhuysen, B. M.; Gruene, P.; Meijer, G.; Fielicke, A. J. Phys. Chem. A 2008, 112, 1139.

(12) Fielicke, A.; Gruene, P.; Meijer, G.; Rayner, D. M. Surf. Sci. 2009, 603,1427 .

(13) Wachs, I. E. Catal. Today 1996, 27, 437.

(14) Schröder, D.; Schwarz, H.; Shaik, S. In Structure and Bonding: Metal-Oxo and Metal-Peroxo Species in Catalytic Oxidations; Meunier, B., Ed.; Springer: Berlin, 2000; Vol. 97, p 91.

(15) Nolan, P. D.; Wheeler, M. C.; Davis, J. E.; Mullins, C. B. Acc. Chem. Res. 1998, 31, 798.

(16) Pramann, A.; Koyasu, K.; Nakajima, A.; Kaya, K. J. Chem. Phys. 2002, 116, 6521.

(17) Zhai, H.-J.; Wang, L.-S. J. Chem. Phys. 2002, 117, 7882. Zhai, H.-J.; Döbler, J.; Sauer, J.; Wang, L.-S. J. Am. Chem. Soc. 2007, 129, 13270. (18) Zhai, H.-J.; Wang, B.; Huang, X.; Wang, L.-S. J. Phys. Chem. A 2009, 113,9804 .

(19) Molek, K. S.; Jaeger, T. D.; Duncan, M. A. J. Chem. Phys. 2005, 123,144313

(20) Asmis, K. R.; Brümmer, M.; Kaposta, C.; Santambrogio, G.; von Helden, G.; Meijer, G.; Rademann, K.; Wöste, L. Phys. Chem. Chem. Phys. 2002, 4, 1101. Asmis, K. R.; Meijer, G.; Brümmer, M.; Kaposta, C.; Santambrogio, G.; Wöste, L.; Sauer, J. J. Chem. Phys. 2004, 120, 6461. Asmis, K. R.; Santambrogio, G.; Brümmer, M.; Sauer, J. Angew. Chem., Int. Ed. 2005, 44, 3122. Asmis, K. R.; Sauer, J. Mass Spectrom. Rev. 2007, 26, 542.

(21) Fielicke, A.; Meijer, G.; von Helden, G. J. Am. Chem. Soc. 2003, $125,3659$.

(22) Fielicke, A.; Meijer, G.; von Helden, G. Eur. Phys. J. D 2003, 24, 69.

(23) Zemski, K. A.; Bell, R. C.; Castleman, A. W., Jr. J. Phys. Chem. A 2000, 104, 5732. Zemski, K. A.; Justes, D. R.; Castleman, A. W., Jr. J. Phys. Chem. A 2001, 105, 10237. Zemski, K. A.; Justes, D. R.; Castleman, A. W., Jr. J. Phys. Chem. B 2002, 106, 6136.

(24) Feyel, S.; Schröder, D.; Rozanska, X.; Sauer, J.; Schwarz, H. Angew. Chem., Int. Ed. 2006, 45, 4677. Feyel, S.; Döbler, J.; Schröder, D.; Sauer, J.; Schwarz, H. Angew. Chem., Int. Ed. 2006, 45, 4681.

(25) Dong, F.; Heinbuch, S.; Xie, Y.; Bernstein, E. R.; Rocca, J. J.; Wang, Z.-C.; Ding, X.-L.; He, S.-G. J. Am. Chem. Soc. 2009, 131, 1057.

(26) Athanassenas, K.; Kreisle, D.; Collings, B. A.; Rayner, D. M.; Hackett, P. A. Chem. Phys. Lett. 1993, 213, 105.

(27) Green, S. M. E.; Alex, S.; Fleischer, N. L.; Millam, E. L.; Marcy, T. P.; Leopold, D. G. J. Chem. Phys. 2001, 114, 2653.

(28) Calaminici, P.; Flores-Moreno, R.; Köster, A. M. Comput. Lett. 2005, 1,164

(29) Wu, Z. J.; Kawazoe, Y.; Meng, J. J. Mol. Struc.: THEOCHEM 2006, 764, 123.

(30) Yang, D.-S.; Zgierski, M. Z.; Rayner, D. M.; Hackett, P. A.; Martinez, A.; Salahub, D. R.; Roy, P.-N.; Tucker Carrington, J. J. Chem. Phys. 1995, 103, 5335.

(31) Fielicke, A.; Kirilyuk, A.; Ratsch, C.; Behler, J.; Scheffler, M.; von Helden, G.; Meijer, G. Phys. Rev. Lett. 2004, 93, 023401.

(32) Fielicke, A.; von Helden, G.; Meijer, G. Eur. Phys. J. D 2005, 34, 83.

(33) Gruene, P.; Fielicke, A.; Meijer, G. J. Chem. Phys. 2007, 127, 234307.

(34) Oepts, D.; van der Meer, A. F. G.; van Amersfoort, P. W. Infrared Phys. Technol. 1995, 36, 297.

(35) Ahlrichs, R.; Bär, M.; Häser, M.; Horn, H.; Kölmel, C. Chem. Phys. Lett. 1989, 162, 165.

(36) TURBOMOLE - Program Package for ab initio Electronic Structure Calculations, V6.0; Universität Karlsruhe: 2009. Available from www. turbomole.com.

(37) Tao, J.; Perdew, J. P.; Staroverov, V. N.; Scuseria, G. E. Phys. Rev. Lett. 2003, 91, 146401

(38) Weigend, F.; Ahlrichs, R. Phys. Chem. Chem. Phys. 2005, 7, 3297. 
(39) Johansson, M. P.; Lechtken, A.; Schooss, D.; Kappes, M. M.; Furche, F. Phys. Rev. A 2008, 77, 053202.

(40) Andrae, D.; Haeusermann, U.; Dolg, M.; Stoll, H.; Preuss, H. Theor. Chim. Acta 1990, 77, 123.

(41) Eichkorn, K.; Treutler, O.; Öhm, H.; Häser, M.; Ahlrichs, R. Chem. Phys. Lett. 1995, 240, 283. Eichkorn, K.; Treutler, O.; Öhm, H.; Häser, M.; Ahlrichs, R. Chem. Phys. Lett. 1995, 242, 652. Eichkorn, K.; Weigend, F.; Treutler, O.; Ahlrichs, R. Theor. Chem. Acc. 1997, 97, 119.

(42) Ratsch, C.; Fielicke, A.; Kirilyuk, A.; Behler, J.; von Helden, G.; Meijer, G.; Scheffler, M. J. Chem. Phys. 2005, 122, 124302.

(43) Fielicke, A.; Ratsch, C.; von Helden, G.; Meijer, G. J. Chem. Phys. 2007, 127, 234306.

(44) Fa, W.; Luo, C.; Dong, J. Phys. Rev. B 2005, 71, 245415.

(45) Deglmann, P.; Furche, F.; Ahlrichs, R. Chem. Phys. Lett. 2002 362, 511. Deglmann, P.; May, K.; Furche, F.; Ahlrichs, R. Chem. Phys. Lett. 2004, 384, 103.

(46) Zhou, M.; Andrews, L. J. Phys. Chem. A 1998, 102, 8251.

(47) Gehrke, R.; Gruene, P.; Fielicke, A.; Meijer, G.; Reuter, K. J. Chem. Phys. 2009, 130, 034306.
(48) Bakker, J. M.; Satink, R. G.; von Helden, G.; Meijer, G. Phys. Chem. Chem. Phys. 2002, 4, 24.

(49) Brennan, D.; Hayward, D. O.; Trapnell, B. M. W. Proc. Royal Soc. A (London) 1960, 256, 81.

(50) Titov, A. V.; Jagodzinski, H. Surf. Sci. 1985, 152-153, 409.

(51) Ibach, H.; Mills, D. L. Electron Energy Loss Spectroscopy and Surface Vibrations; Academic Press: New York, 1982; pp 142-151.

(52) Spectroscopic Characterization of Heterogeneous Catalysts (Stud. Surf. Sci. Catal., Vol. 57); Fierro, J. L. G., Ed.; Elsevier: Amsterdam, 1990; part B, pp 163-165.

(53) Franchy, R.; Wuttig, M.; Ibach, H. Surf. Sci. 1988, 203, 489.

(54) Jakob, P.; Persson, B. N. J. J. Chem. Phys. 1998, 109, 8641.

(55) Dürr, H.; Fauster, T.; Schneider, R. Surf. Sci. 1991, 244, 237.

(56) Dürr, H.; Baddorf, A. P. Surf. Sci. 1994, 312, 369.

(57) Stietz, F.; Meister, G.; Goldmann, A.; Schaefer, J. A. Surf. Sci. 1995, 339, 1.

JP102084N 